\title{
Low Level Millimetric Waves Exposure in Post Traumatic Surgery Pain Relief : A 2 Cases Report
}

\author{
Debouzy JC ${ }^{1,2 *}$, Crouzier $\mathbf{D}^{2,3}$, Rech $\mathbf{S}^{\mathbf{1}}$ and Bachelet Campagne $\mathbf{C}^{4}$ \\ ${ }^{1} 7^{\text {th }}$ French Army Medical Center, Quartier Reyniès, 38760 Varces, France \\ ${ }^{2}$ Armed Forced Biomedical Research Institute, Non-conventional threats Department, place V Andrée, 91233 Bretigny sur Orge \\ cedex, France
}

${ }^{3}$ Remedee Labs; 35 chemin du vieux chêne, 38240 Meylan, France

${ }^{4}$ DSIN, rue Cornelie Gemond, 38000 Grenoble France

*Corresponding author: Jean Claude Debouzy, French Army Medical Center, Armed Forced Biomedical Research Institute, Non-conventional threats Department, 60, rue du château, 38660 La Terrasse, France

\begin{tabular}{|c|c|}
\hline ARTICLE INFO & ABSTRACT \\
\hline Received: 豐 January 11, 2021 & $\begin{array}{l}\text { Practicing high-risk sports, such as skiing, frequently leads to osteo articular } \\
\text { traumatisms requiring complex surgery. The postoperative period is often painful, even }\end{array}$ \\
\hline Published: February 18, 2021 & when major analgesic medications are used. We report 2 cases of ski accidents: one \\
\hline $\begin{array}{l}\text { Citation: Debouzy JC, Crouzier D, Rech } \\
\text { S, Bachelet Campagne C. Low Level } \\
\text { Millimetric Waves Exposure in Post } \\
\text { Traumatic Surgery Pain Relief : A } 2 \text { Cases } \\
\text { Report. Biomed J Sci \& Tech Res 34(1)- }\end{array}$ & $\begin{array}{l}\text { in a very painful postoperative recovery time. In one case, exposure of the wrist to low } \\
\text { level electromagnetic wave in the millimetric frequency (MMW, } 60 \mathrm{GHz} \text {, continuous wave) } \\
\text { by means of a device designed for wellness or to improve or initiate sleep, resulted in } \\
\text { almost complete pain relief and the removal of analgesics, allowing active rehabilitation. } \\
\text { While the results in the other case seemed less spectacular, the use of the device provided } \\
\text { physiological support to the mechanism of the MMW's analgesic properties. }\end{array}$ \\
\hline
\end{tabular}
2021. BJSTR. MS.ID.005486.

Keywords: Pain; Sport Traumatism; Millimetric Wave

\section{Introduction}

The practice of winter sports, skiing or snowboarding, although widespread, remains a risky activity. 144,000 injuries were taken care of by mountain doctors during the 2018-2019 season in France, representing an incidence of 2.55 injuries per 1,000 skiers per day $[1,2]$. The majority of accidents result either from a fall or a collision with a third party. In the latter situation, the speed of the skier upstream (the one hitting), causes injuries, often of the most serious kind [3]. Under the age of 30, most injuries involve wrists, shoulders, knees, and head (mainly snowboarding accidents). After the age of 31, injuries to the knees (in particular the rupture of cruciate ligaments) and shoulders (mainly dislocations) are predominantly related to skiing $[4,5]$. These situations are illustrated by two cases presented in this article. With regard to knee damage, as in case 1 , it mostly concerns sprains or ruptures of the anterior cruciate ligament [6], alone or accompanied by lateral ligament injuries. An anterior cruciate ligament injury results from a fall, with the foot fixed to the ground, producing valgus, flexion, and external rotation, all in hyper-extension. In addition to the initial cracking sensation, combined with hydarthrosis and instability of the knee, intense pain often immediately occurs. These conditions are frequently compounded by sprained lateral ligaments and meniscus lesions, as in case 1 . In case 2 , the lesions concern the upper limbs and in particular a complicated scapulohumeral dislocation-fracture with functional impairment and immediate pain of great intensity.

What these two cases have in common is that they both involve severe pain and the deliberate use of a millimetric-wave device (MD). This device was originally designed to improve well-being and, in particular, to enable (at least partial) sleep to be restored. It turns out that the use of external millimetric wave (MMW) exposure had been proposed in the late $19^{\text {th }}$ century in several of the former Eastern-Bloc [7,8] countries. Among the various applications $[9,10]$, wound healing [11] and the relief [12] of chronic pain were clearly identified. Such effects were mainly related to the peripheral nervous stimulation induced by the MMW, leading to 
central endorphin secretion and thus to a hypoalgesic effect. This was supported, in particular, by several neurophysiological studies in animal experiments $[13,14]$. Recent technological advances in high-speed electronics and miniaturization have allowed to develop inexpensive, integrated hyper-frequency emitters that can be simply worn by the patient like a watch (see (Figure 1), Millimetric device, MD). The DM is mounted as a watchstrap. The arrow indicates the $2 \mathrm{~cm}^{2}$ rectangular antenna on the path of the median nerve; the battery is placed on the other side of the wrist. This device emits a continuous electromagnetic wave of $60 \mathrm{GHz}$ at a power density of $14 \mathrm{~mW} / \mathrm{cm}^{2}$ over $2 \mathrm{~cm}^{2}$ skin surface. Positioned on the inner side of the wrist ( 2 sessions of 30 minutes per day), it is thus in close contact with the median nerve. The two cases reported in this article present the effects of MMW exposure on post-surgical or post traumatic physical suffering.

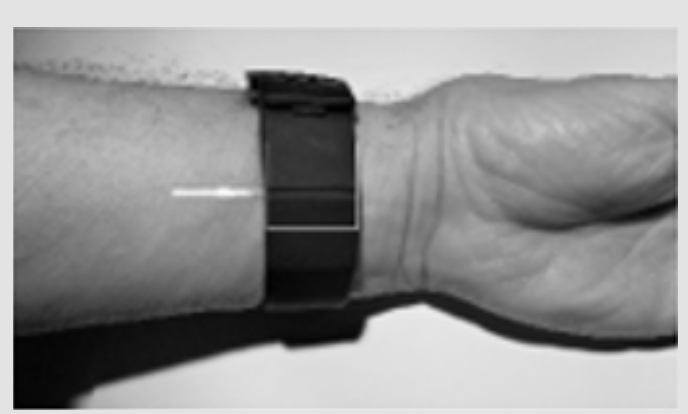

Figure 1: The MD, mounted as a watchstrap. The arrow indicates the $2 \mathrm{~cm}^{2}$ rectangular antenna on the path of the median nerve; the battery is placed on the other side of the wrist.

\section{Cases Description}

First patient, Mrs Marie R., 37 years old, a well-trained athlete (mountain military environment), with no history of surgery, ongoing medical treatment, or addiction.

Facts and initial medical care: during a day of recreational skiing (December 2019), while at a standstill, Marie's left leg was pulled by her child's skidding, cramped. The slip resulted in a fall with a rotating movement of her left leg in hyper-extension, while her foot kept fixed to the ground. She felt an internal cracking sound as her knee locked in a $30^{\circ}$ flexion. The initial pain was evaluated at 5 (according to the visual analogic pain scale, VAS [15]. The knee was immobilized with a Zimmer splint, which was difficult to endure. A medical treatment, i.e. anti-inflammatories (Ketoprofene100) and major analgesics (Tramadol/paracetamol/Ixprim) limited the pain (VAS of 5) while a flessum gradually appeared. This finally led to an MRI examination after 7 days, which showed a total rupture of the anterior cruciate ligament (posterior uninjured), associated with a partial rupture of the anterior lateral ligament and a tear of the external meniscus with bucket handle. The immediate treatment against the flessum consisted of hyper-extending the knee, under anaesthesia (Meopa gas), and fixing the position with the Zimmer splint. At this time the pain was syncopal, with absolute insomnia.
High doses of Tramadol $(3 \times 50)$ and Paracetamol, only partly limited VAS to 6.

Two weeks later, a surgery was performed: classic ACL technique (French DIDT) for the anterior cruciate ligament [16,17], and sutures of the external meniscus (the lateral ligament was not modified). The surgery was combined with a Zimmer splint. After 3 days, the pain level was still over 5 despite the maximum recommended daily analgesic doses (Ketoprofene 100mg, Tramadol 200 mg, Paracetamol 4g, icing). Spontaneous evolution, thanks to the removal of the splint, allowed to reduce such doses, with at this time a VAS of 3. Rehabilitation phase and use of MMW - after 20 days: from the first rehabilitation session, extreme pain reappears (VAS of 8), quadricipital muscule atrophy sets in. The use of major analgesics (Ketoprofene 100mg, Tramadol $200 \mathrm{mg}$, Paracetamol 4g), in high daily doses, is again required to achieve an approximate VAS of 5. This led Mrs Marie R to test the MMW bracelet, twice a day to begin with. As soon as she started (i.e. on day 28), the VAS dropped to 2 and all medical treatment was immediately stopped (use of ice only, locally). Thereafter, only one use of the bracelet per day was maintained, and Marie was able to undertake regular rehabilitation (VAS 2). Furthermore, she began to space out the bracelet sessions, and managed to walk with a single crutch. The crutches were removed in the following weeks, which finally enabled her to stop using the bracelet. The different stages are shown in (Table 1 ) below.

Table 1: Evolution Of The Clinical Case 1 and Associated Pain (VAS).

\begin{tabular}{|c|c|c|c|}
\hline Day & Circumstances & $\begin{array}{c}\text { VAS without } \\
\text { treatment }\end{array}$ & $\begin{array}{c}\text { VAS under } \\
\text { treatment }\end{array}$ \\
\hline 0 & Accident & Not quoted & 5 \\
\hline $1-20$ & $\begin{array}{c}\text { First immobilisation } \\
\text { with splint }\end{array}$ & $8-9$ & 6 \\
\hline $20-25$ & Post surgery & --- & 5 to 3 \\
\hline $25-28$ & Rehabilitation & 8 & 5 \\
\hline 28 & MMW bracelet 2/day & 2 & --- \\
\hline $40-100$ & $\begin{array}{c}\text { Bracelet 5days a } \\
\text { week }\end{array}$ & 2 & - \\
\hline
\end{tabular}

Second patient, Mrs Kate B., 54 years old.

Facts and initial medical care: while skiing, Mrs Kate B was struck from behind by a snowboarder, causing a violent projection on the ground. Initial pain was extreme (VAS of 9). She presented with an antero-inferior dislocation of the right shoulder, associated with complete lesion of the brachial plexus. The initial clinical examination found complete homolateral anesthesia and motor impairment in the territories C5 to T1. Complementary explorations confirmed a complete tear of the supraspinatus, adipose within the infraspinatus muscle, associated with tuberosity impaction with a notch against the antero-inferior edge of the glenoid. Pain management required major painkillers (Paracetamol, Tramadol, Pregabalin), leading to limited relief (VAS of 6). Recovery and 
rehabilitation extended over 1 year, including reconstructive surgery of the rotator cuff (new period at VAS $=9$ ). These finally led to a partial recovery of the paralysis and an incomplete functional shoulder recovery, in February 2020. The first use of the remedy on the right wrist (side of the trauma) took place from 12 to 14 March. An increase in the feeling of crushing and numbness in the right-hand fingers was observed, whereas no noticeable effect on dysesthesia or shoulder pain was present. In the hypothesis of an alteration of nerve conduction by its paraparetic limb, the wrist on which the device was worn was changed, i.e. from right to left wrist ( 2 to 3 times a day, from 14 to 19 March).

Although it was difficult to assess the decrease in pain intensity and to dissociate it from a possible placebo effect, or from the still ongoing recovery of the shoulder as well as the nervous recovery of the hand and forearm, a better quality of sleep at night was clearly noted, with significantly fewer night-time awakenings due to shoulder pain (VAS lowered from 4-5 to 2-3). upward movements as well as external rotation. In addition, each time she woke up it took Kate less time to go back to sleep and she would lie down longer on her right side/shoulder, returning to positions similar to those before the accident. Moreover, when she rolled over in her sleep, she could lie down again on her injured right side. She was also able to lift her right arm more easily, i.e., with less pain, during the day. As muscle weakness was still present, moving required efforts but was much less limited by the pain. This was particularly noticeable in forearm extension and neurological evolution was more surprising: although the numbness was always more or less present depending on the positions of the arm and hand, an overall decrease in such diffuse pain was noted. As for the sensation of electrical discharges and crushing of the fingers, it was significantly less painful for active movements (especially the fingers and wrist extension). Furthermore, a deliberate interruption in the use of the device then led to the reappearance of pains and shocks from, fingers to shoulder, insomnia, and night-time pains. (Table 2) summarizes the events that occurred during this period.

Table 2: Evolution Of The Clinical Case 2 and Associated Pain (VAS).

\begin{tabular}{|c|c|c|c|}
\hline Date & Circumstances & $\begin{array}{c}\text { VAS without } \\
\text { treatment }\end{array}$ & $\begin{array}{c}\text { VAS under } \\
\text { treatment }\end{array}$ \\
\hline February 2019 & Accident & 9 & 6 \\
\hline June & Emergency treatment & - & \\
\hline March 2020 & $\begin{array}{c}\text { Rehabilitation } \\
\text { physiotherapy... }\end{array}$ & $4-5$ & \\
\hline March 12-19 & $\begin{array}{c}\text { MMW bracelet 2-3/day } \\
\text { right wrist }\end{array}$ & 5 & --- \\
\hline March 20-24 & $\begin{array}{c}\text { MMW bracelet 2-3/day } \\
\text { left wrist }\end{array}$ & $2-3$ & -- \\
\hline March 24-28 & Stop device & $4-5$ & \\
\hline
\end{tabular}

Copyright@ Debouzy JC | Biomed J Sci \& Tech Res | BJSTR. MS.ID.005486.

\section{Discussion}

The observations presented here relate the effects of local exposure to low power millimetric radiation $\left(60 \mathrm{GHz}, 14 \mathrm{~mW} / \mathrm{cm}^{2}\right.$, continuous waves) on recovery in the post-surgical phase after severe sports trauma. In both cases, the MD was purchased and tested in an attempt to help achieve a little well-being and sleep, strongly affected by pain. This proved to be the case in the first instance, where both the surgery and the immobilization of the knee induced such suffering (syncopal, VAS=9) that massive use of major antalgics was necessary to obtain a barely tolerable situation (VAS=6). The almost total sedation (VAS\#2) obtained from the first sessions (twice daily for $1 / 2$ hour), allowing the immediate cessation of any analgesics, is in itself a major result. Directly related to this sedation, an equally important result was the ability to undertake functional rehabilitation (fast walking without crutches, knees flexion amplitudes, amyotrophy ...), and thus returning to a normal personal and professional life for this very active person. The improvement obtained in the second case is less spectacular but provides physiological insights about the mechanisms involved in pain relief. Indeed, this trauma involved both a significant osteoarticular lesion (antero-internal dislocation of the shoulder with fracture of the glenoid rim) and total paralysis (sensory and motor) of the upper limb caused by dilaceration of the brachial plexus. To assess pain and the effects of MMWs, it is therefore necessary to dissociate the consequences of both the local trauma and the associated surgery, the progression of the paralysis, and the specific effect of MMW (perception conduction of information).

Hence, the relief of osteoarticular pain appears to be well identified, both in terms of well-being, sleep and functional recovery, when the device was set on the contralateral wrist. This point leads to the neurological evolution, where the spontaneous regression of pararesia was obviously present. However, it points out that adjusting the device homolaterally to the lesion appeared ineffective in pain relief. Our mechanistic hypothesis in MMW hypoalgesic is that local stimulation of the peripheral cutaneous receptors properties leads, via nervous centripetal information, to central nervous secretion of endorphins [6-8]. This hypothesis is supported by several experimental results and publications $[9,10]$. For instance, using the cold-water tail-flick test (cTFT) as a quantitative indicator in a series blind experiments on pain in mice, Radjevski [11], tested the hypoalgesic effect of a single exposure of mice to low power electromagnetic millimetre waves (MW) with MMW exposure characteristics very similar to those used in the present report: $61.22 \mathrm{GHz}$; incident power density 5 to $15 \mathrm{~mW} / \mathrm{cm}^{2}$ , for an exposure duration of 15 minutes on the hairless skin of the footpad. Hence, exposed mice were able to resist cold harmful stimulation for more than twice as long as unexposed animals. Furthermore, the deafferentation of the area of exposure by the unilateral transection of the sciatic nerve resulted in a complete loss of the hypoalgesic effect. 


\section{Conclusion}

The two cases presented here show a clinical improvement obtained fortuitously by the use of a device intended for another purpose, namely well-being or sleep. The most important clinical finding from this case study is that low power exposure of the wrist $(60 \mathrm{GHz} \mathrm{CW}$ MMW) can significantly improve functional performance and quality of life after major post- traumatic surgery with as little strain as wearing a watch. Besides, the second case strongly supports the mechanisms involved in such hypoalgesic properties, i.e. peripheral MMW stimulation under normal nerve conduction, leads to an increase in brain endorphin level, resulting in symptoms reduction. It is noteworthy that the MMW device, devoid of any deleterious side effects, allows for a considerable reduction in medical treatments based on major painkillers thus allowing a better post-surgery functional recovery. Extensive clinical trials have to be performed to confirm these properties, such as those currently undertaken in cardiac surgery or the fitting of knee or hip prostheses, for instance.

\section{Acknowledgement}

Many thanks to Carolyne Ramusga-Bassani, (Formation and Talents Company) for manuscript correction and fruitful discussions.

\section{References}

1. Association médecins de montagne. http://www.mdem.org/france/ DT1190189670/page/Les-chiffres.html

2. Bacquaert $P$ (2014) Les traumatiques fréquents de la pratique du ski. Institut de recherche du bien-être, de la médecine et du sport-santé.

3. Schoenhuber H, Panzeri A, Porcelli S (2018) Alpine Skiing Injuries: Prevention and Management (Sports and Traumatology), Landreau P series (Edn.)., Springer international publishing.

4. Röhrl S, Hauser W, Schaff P, Rosemeyer B (1994) Pattern of injuries in skiing worldwide. Can current guidelines for adjusting ski bindings reduce injuries in the future? Sportverletz Sportschaden 8(2): 73-82.

5. Basquez CA, Gardner E, Samuel A, Webb ML (2018) Injury patterns and risk factors for orthopaedic trauma from snowboarding and skiing: A national perspective, Knee Surgery Sports Traumatology Arthroscopy 26(9): 1916-1926.

6. De Roulet A, Inaba K, Strumwasser A, Chouliara K, Lam L, et al. (2017) Severe injuries associated with skiing and snowboarding: A national trauma data bank study. J Trauma Acute Care Surg 82(4): 781-786.

7. Rojavin MA, Radzievsky AA, Cowan A, Ziskin MC (2000) Pain relief caused by millimeter waves in mice: Results of cold-water tail flick tests. Int J Radiat Biol 76(4): 575-579.

8. Radzievsky AA, Gordiienko OV, Alekseev S, Szabo I, Cowan A, et al. (2008) Electromagnetic millimeter wave induced hypoalgesia: Frequency dependence and involvement of endogenous opioids. Bioelectromagnetics 29(4): 284-295.

9. Pakhomov AG, Akyel Y, Pakhomova ON, Stuck BE, Murphy MR (1998) Current State and Implications of Research on Biological Effects of Millimeter Waves: A Review of the Literature. Bioelectromagnetics 19(7): 393-413.

10. Lysenyuk VP, Samosyuk IZ, Kulikovich YN, Kozhanova AK (2000) Experimental study on the low-intensity millimeter-wave electromagnetic stimulation of acupuncture points. Acupunct Electrother Res.25(2): 91-99.

11. Radzievsky A, Gordiienko 0, Cowan A, Alekseev A, Ziskin M (2004) Millimeter wave induced hypoalgesia in mice: Dependence on type of experimental pain. IEEE Trans Plasma Sci 32: 1634-1643.

12. Vorobyov VV, Khramov RN (2002) Hypothalamic effects of millimeter wave irradiation depend on location of exposed acupuncture zones in anesthetized rabbits. Am J Chin Med 30(1): 29-35.

13. Bagatskaya EV, Gura EV, Limansky YP (2008) Analgesia Induced by Microwave Irradiation of an Acupuncture Point in Mice with Visceral Pain: Role of the Cerebral Opioid System. Neurophysiology 40: 358-362.

14. Chuyan EN, Dzheldubayeva E (2006) Antinociceptive effects of low-intensity extrahigh-frequency electromagnetic radiation. Neurophysiology 38: 277-285.

15. Haefeli M, Elfering A (2006) Pain assessment. Eur Spine 15(S1): S17-S24.

16. Honkamp NJ (2008) Anterior cruciate ligament injuries in adults. In: JC DeLee (Eds.)., Delee and Drez's Orthopaedic Sports Medicine: Principles and Practice, (3 ${ }^{\text {rd }}$ Edn.)., Philadelphia: Saunders Elsevier 2: 1644-1676.

17. Micheo W, (2015) Anterior cruciate ligament tear. In: WR Frontera (Eds.)., Essentials of Physical Medicine and Rehabilitation, ( $3^{\text {rd }}$ Edn.)., 2015 Philadelphia: Saunders pp. 324-330.

\section{ISSN: 2574-1241}

DOI: 10.26717/BJSTR.2021.34.005486

Debouzy JC. Biomed J Sci \& Tech Res

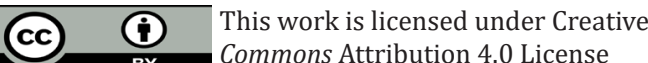

Submission Link: https://biomedres.us/submit-manuscript.php

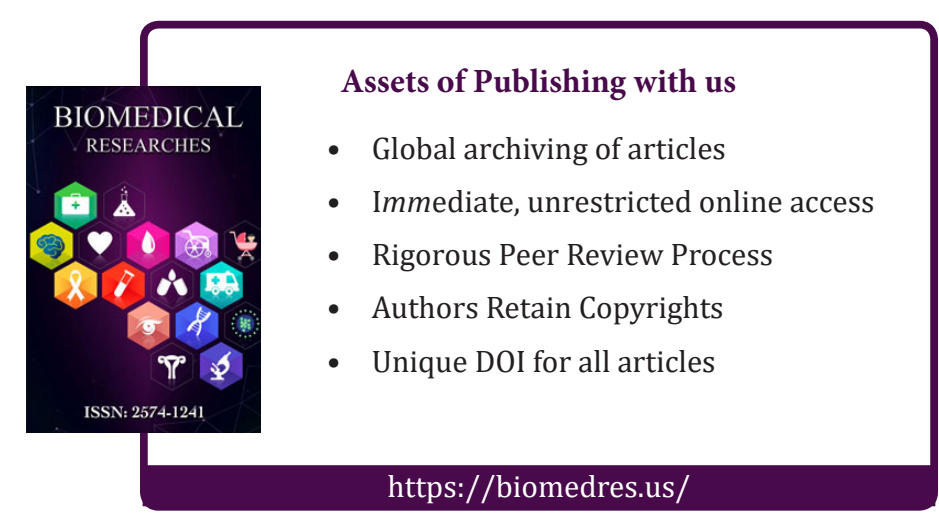

